\title{
Necrópolis romana de Carmona. Un proyecto innovador de gestión cultural (1881-1930)
}

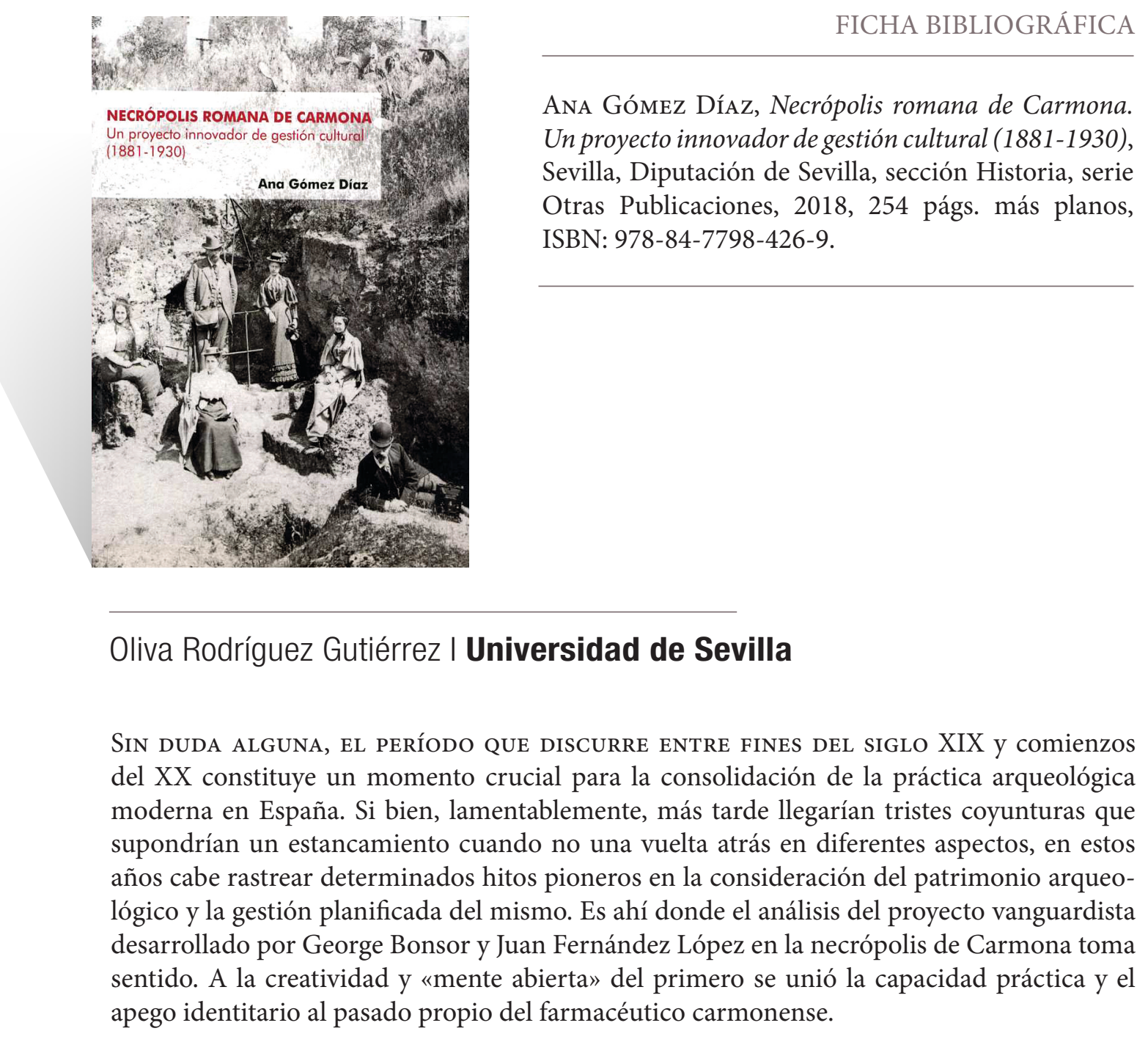


Lo que empezó siendo un proyecto personal, en el que ambos comprometieron buena parte de su patrimonio, derivó en el diseño de un sistema de gestión sostenible, al que se sumarían donaciones privadas, subvenciones públicas -las menos- y otras inteligentes y estudiadas estrategias de beneficio (cap. 6); la venta de recuerdos, la prestación de servicios de restauración a visitantes o la puesta en cultivo de terrenos incluidos en la propiedad serán algunas de ellas, al margen de la más tradicional y previsible venta de entradas. Que este modelo innovador de «marketing cultural»-que aún hoy se mira con cierto recelo- no estuvo errado se pone de manifiesto en el hecho de que la necrópolis de Carmona pudiera convertirse, con la definición del modelo autonómico, en uno de los ocho Conjuntos Arqueológicos andaluces, en la cúspide de la un tanto malograda Red de Espacios Culturales de Andalucía (RECA).

Al margen de los numerosos estudios realizados a lo largo de décadas sobre la controvertida interpretación histórica y cultural de este singular conjunto funerario, en época más reciente ha aumentado notablemente el interés por su vertiente patrimonial. En este último recorrido científico se inserta el trabajo de Ana Gómez Díaz. La autora, en su calidad de responsable desde hace ya casi dos décadas del Castillo de Mairena del Alcor, última residencia de Bonsor, es una excelente conocedora de la labor desarrollada por el inglés -y francés- en la región. Su estudio ha incorporado no solamente abundante y minuciosa documentación conservada en diferentes archivos sino que, más aún, refleja una verdadera sintonía con el talante personal con el que George Bonsor se acercó, a lo largo de toda su vida, al patrimonio andaluz, su conocimiento y su salvaguarda.

De hecho, sólo la revisión de una documentación que, a primera vista, podría parecer anecdótica y que incluye desde entradas, folletos, postales, fotografías, hasta minuciosos planos y una dilatada correspondencia, le ha permitido la reconstrucción del ilusionante proyecto. Fraguado desde Carmona, llegó a incorporarse a los circuitos de prestigiosos turoperadores internacionales como la compañía británica Thomas Cook \& Son, o a quedar incluido en influyentes guías de viajes como la célebre Michelin. Es precisamente esta documentación la que ha posibilitado conocer el papel influyente de G. Bonsor como asesor, por ejemplo, de J. R. Mélida en sus intervenciones patrimoniales en Mérida. $\mathrm{O}$, en esa misma línea, consolidar definitivamente su reconocimiento como uno de los «padres» de la arqueología española moderna, habiendo estado en contacto e incluso colaborado directamente con otros nombres de referencia como P. Paris, Juan de Dios de la Rada y Delgado, Arthur Engel, Fidel Fita o Archer Huntington, entre otros. Sus planos y dibujos, más allá de la calidad estética propia de su formación artística, reflejan una verdadera preocupación por la documentación y el registro. Buena parte de ellos ha sido reproducida en este libro, con una calidad que se debe al buen hacer de su autora y al esmero del Servicio de Publicaciones de la Diputación de Sevilla, responsable de la edición.

La obra se organiza de acuerdo a una estructura orgánica y coherente en la que cabe recocer la propia progresión lógica de todo proyecto arqueológico moderno. Ello permite ir recorriendo las líneas maestras de la propuesta del afortunado tándem Bonsor-Fernández López, que comenzó en 1881 y que llegó a su fin con la muerte del primero en 1930 y la cesión al Estado del yacimiento. Su carácter innovador está ya presente desde la misma metodología arqueológica de campo y el concienzudo registro de los datos, en la que se considera la primera excavación sistemática de la Península ibérica. No olvidemos las actividades mucho menos controladas pero más propias de su época que, por los mismos años, se estaban 
desarrollando en la vecina Itálica, a iniciativa, por ejemplo, de otro importante personaje de los círculos eruditos de la arqueología sevillana como era la Condesa de Lebrija, doña Regla Manjón. El diseño integral gestado para la necrópolis de Carmona suponía el salto de la concepción anticuaria a la preocupación moderna por la interpretación de los restos y su presentación al público de forma atractiva y comprensible. Esta se acompañaba, incluso, de propuestas de carácter «experiencial», de las que hoy hacen las delicias de propios y extraños en el campo del turismo cultural globalizado y democrático.

Así, en los diferentes capítulos se va avanzando, en primer lugar, por los trabajos arqueológicos llevados a cabo para el descubrimiento de diferentes tumbas (cap. 3); en esta nueva etapa, claramente distanciados desde el punto de vista procedimental de las incursiones previas en la necrópolis. Fue, precisamente, una excavación más depurada y, sobre todo, un registro más escrupuloso, tanto en lo referido a la documentación gráfica como a la conservación y clasificación de los materiales recuperados, lo que posibilitó ulteriores apuestas por la presentación de resultados al público y la creación de un museo de sitio (cap. 5). A este, en cierta forma, aún debe mucho el actual Conjunto Arqueológico, constituido como tal a comienzos de la década de los noventa, integrado en el organigrama de la Consejería de Cultura de la Junta de Andalucía.

El proyecto de Bonsor y Fernández López se significa, además, por ser una apuesta personal y de carácter privado - de ahí su mayor singularidad-. Poseía unos objetivos claros que pasaban, por ejemplo, por la adecuación del yacimiento para la visita (cap. 4), entendido ya en este momento como producto turístico de calidad, a imagen de otras experiencias que ya se estaban desarrollando en ámbito internacional y de las que era buen conocedor, especialmente, el curioso y receptivo G. Bonsor. De hecho, una de las principales y más atractivas aportaciones de este libro es la contextualización de la labor de estos entusiastas en el nacimiento, en ámbito internacional, del turismo cultural tal y como lo entendemos hoy en día (cap. 2).

El trabajo de Ana Gómez consigue, desde una aproximación historiográfica, frecuentemente denostada en el marco de nuestras disciplinas, trazar un evocador panorama de la realidad histórica de la época. Una etapa floreciente en Europa en la que, especialmente la creciente y adinerada burguesía, buscará nuevos símbolos de estatus. El acceso a otras culturas y entornos, en ocasiones con una mentalidad heredada, por qué no, del todavía muy reciente pasado colonial, será el objetivo de la aristocracia anglosajona.

En definitiva, sorprende, al leer el libro de Ana Gómez, lo moderno de esta experiencia en la necrópolis de Carmona y, de forma más general, de las rutas altamente especializadas para la época por la comarca de Los Alcores en la que esta se enmarcaba. Más aún, enrojece conocer esta pionera propuesta cuando, un siglo después, en muchos yacimientos creemos estar innovando con iniciativas -a las que denominados «Arqueología pública»- que ya pueden ser rastreadas en las de estos visionarios. Avergüenza, de hecho, comprobar que su sensibilidad no caló lo suficiente en sus contemporáneos ni su senda supo ser continuada por las administraciones públicas a las que se legó un producto patrimonial exitoso y sin precedentes. En la coyuntura actual, en la que en muchas ocasiones faltan los medios tanto humanos como presupuestarios para un adecuado rendimiento social de nuestros bienes patrimoniales, cabría reflexionar sobre modelos alternativos de gestión. Estos, mixtos o incluso priva- 
dos, tutelados oportunamente por las administraciones públicas, no deberían significar, por ello, menoscabo a su correcta tutela y conservación. Obras como la de Ana Gómez, objetiva y analítica a la vez, sirven, de hecho, para llamar la atención sobre la validez, en ocasiones, de aquella máxima que sostiene que «cualquier tiempo pasado fue mejor». 